\title{
The relationship between depression, anxiety, and pain catastrophising in cancer patients
}

\author{
Fatih İnci', Habibe İnci², Oğuzhan Kılınçel³, Süleyman Ersoy4, Fatih Karataş', Didem Adahan²
}

'Department of Internal Medicine and Medical Oncology, Karabük University, Turkey

${ }^{2}$ Department of Family Medicine, Karabük University, Turkey

${ }^{3}$ Department of Psychiatry, Sakarya Yenikent State Hospital, Turkey

${ }^{4}$ Department of Family Medicine, University of Health Sciences Umraniye SUAM, Turkey

\section{Abstract}

Introduction: Catastrophising is a person's view of an unreasonable belief and a worse situation than exaggerating its consequences. It is defined as individuals believing that their current condition and physical discomfort will worsen each time or that something will be worse than it actually is. The aim of this study was to evaluate the relationship between depression and anxiety and pain catastrophising in cancer patients.

Material and methods: Fifty-five cancer patients who were followed and treated in the Oncology Outpatient Clinic were included in the study. The age, gender, marital status, occupation, and psychiatric history of the participants were recorded. A socio-demographic data form, Beck Depression Inventory (BDI), Beck Anxiety Inventory (BAI), and the Pain Catastrophising Scale (PCS) were applied to the participants.

Results: The mean age of the participants was $59.2 \pm 12.7$ years, and $40 \%$ were female. When the total BDI and BAI scale scores of cancer patients were evaluated, it was seen that they were not depressed in terms of mean value $(p=0.112)$, but they were in the anxiety scale $(p<0.05)$. There was a positive correlation between depression and anxiety, as well as depression and anxiety and pain catastrophising $(p<0.001, r=0.782)$. While the PCS subscales "helplessness" and "rumination" scores were significantly higher in cancer patients with depression and anxiety $(p<0.001)$, the "magnification" score was significantly higher in cancer patients with anxiety $(p<0.001)$. The Pain Catastrophising Scale total score increased with increasing BDI and BAI severity $(p<0.001)$, while the BDI and BAI scores were found to be significantly higher in females than males $(p<0.001)$.

Conclusions: It was found that cancer patients were generally not depressed but were anxious, and the catastrophising of pain increased with increasing depression and anxiety severity. Health professionals giving care to cancer patients need to be alert to signs of psychological distress in patients experiencing pain.

Key words: cancer patients, depression, anxiety, pain catastrophising.

\section{Corresponding address:}

Fatih İnci, MD, Department of Internal Medicine and Medical Oncology, Karabük University, Turkey, e-mail: fatihinci65@hotmail.com

\section{INTRODUCTION}

Diagnosis of cancer is an emotional, psychological, and physically traumatic experience, which causes anxiety, helplessness, and disability in most patients. Many studies have proven that these changes are often negative and are connected to stress caused by the diagnosis, fear of the disease, and fear of death [1]. One of the most common and disturbing symptoms in patients with cancer is pain. Cancer-related pain is one of the most important problems that affect more than half of cancer patients at any stage of the disease [2]. Estimates indicate that $50-90 \%$ of cancer patients experience pain, and pain is generally caused by the disease itself, side effects of cancer treatment, and/or medical treatments [3]. Pain and emotions constantly influence each other neurophysiologically, and the relationship is reciprocal. In neuro-imaging studies, positive emotions have been shown to neurologically inhibit pain impulses, while negative emotions have been shown to facilitate them [4]. Some studies have reported that cancer patients have more advanced anxiety and depression than the general population [5]. Cancer-re- 
lated distress, clinical depression, and other mood disorders are prevalent in patients with active cancer. Indeed, pain, fatigue, and emotional distress are the three most commonly co-occurring symptoms in patients with cancer [6]. Therefore, it is important to address anxiety and depression because they can create certain difficulties in performing daily activities and also significantly impair the patients' quality of life [7]. Compared to pain-free cancer patients, cancer patients with pain had significantly higher levels of anxiety, depression, and anger [3].

While the word catastrophising means literally a bad ending and disastrous, catastrophising in psychosomatology is used to assess a person's situation, fearing that a physical complaint will worsen each time [8]. The 'helplessness' (which can be defined as an inability to cope effectively with pain) and 'magnification' subscales, which define pain dissatisfaction and expectation of negative results by over-focusing the negative aspects of pain, reflect the cognitive content of psychopathologies such as anxiety and depression accompanying cancer. The 'rumination' subscale, which measures anxiety, the disability to prevent pain-related thoughts and to distract attention from these thoughts, is associated with dysfunctional coping behaviours developed against painful situations [9]. In many studies it has been shown that maladaptive coping strategies such as catastrophising are associated with more severe pain level and high-level depression, while patients with adaptive coping strategies have less pain and less stress [10,11]. Fear of pain develops as a result of a cognitive interpretation of pain as threatening (pain catastrophising), and this fear leads to avoidance behaviours, followed by disability, disuse, and depression [12].

The aim of this study was to evaluate the relationship between depression and anxiety and pain catastrophising in cancer patients.

\section{MATERIAL AND METHODS}

This cross-sectional, nonrandomised-prospective study included 55 cancer patients who were followed up and treated at the Oncology Clinic of Karabük Training and Research Hospital. Informed written consent form was obtained from the participants. Age, gender, marital status, educational status, occupation, and psychiatric history of the participants were recorded. The questionnaire form prepared by the researchers was evaluated by completing the Beck Depression Inventory (BDI), Beck Anxiety Inventory (BAI), and Pain Catastrophising Scale (PCS). For this study, approval was obtained from the local Ethics Committee.

\section{Beck Depression Inventory}

This is a self-report scale consisting of 21 questions used to assess depression levels. It was developed by Beck et al., and the validity and reliability study in Turkey was conducted by Hisli [13, 14]. Physical, emotional, cognitive, and motivational symptoms of depression are measured. The scale aims to objectively determine the degree of depression symptoms. Each of the 21 items has 4 options, and each item is given a score of $0-3$. The scores range from 0 to 63 , and a higher score indicates more severe depression. If the total value of BDI was 9 or less, it was evaluated as 'no depression', 10-16 as 'mild', 17-23 as 'moderate', and 24 and more as 'severe depression'.

\section{Beck Anxiety Inventory}

Developed by Beck et al., this scale is a self-assessment scale used to determine the frequency of anxiety symptoms experienced by individuals [15]. It is a Likert-type scale consisting of 21 items and scored between 0 and 3. Validity and reliability in Turkey were made by Ulusoy et al. [16].

\section{Pain catastrophizing scale}

It was developed in 1995 by Sullivan et al. to identify catastrophic thoughts or feelings about pain that patients experience and ineffective coping strategies. It is a Likert-type self-assessment scale consisting of 13 items. Each item is evaluated between 0 and 4 points. The total score ranges from 0 to 52 . It includes rumination, magnification, and helplessness subscales. High scores indicate a high level of disaster [8].

\section{Inclusion and exclusion criteria}

Patients meeting the following criteria were included in the study: older than 18 years of age and diagnosed with cancer (stomach, colon, rectum, breast, lung, ovarian cancer). Patients who did not want to participate in the study, patients with advanced stage cancer, those with a previous diagnosis of psychiatric disease, pregnant women, and patients with missing sociodemographic data were excluded from the study (Figure 1).

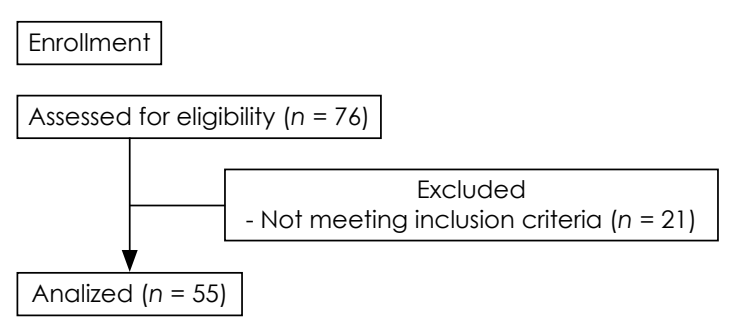

Figure 1. Flowchart of the study 
Table 1. Sociodemographic and clinical characteristics of participants

\begin{tabular}{lc}
\hline Variables & Cancer patient \\
\hline Age (years), median (range) & $59.2 \pm 12.7(33-82)$ \\
\hline Gender, $n$ (\%) & $22(40)$ \\
\hline Woman & $28(60)$ \\
\hline Male & \\
\hline Marriage status, $n$ (\%) & $51(92)$ \\
\hline Married & $2(3)$ \\
\hline Single & $2(3)$ \\
\hline Widow & \\
\hline Education, $n$ (\%) & $7(12)$ \\
\hline Literate & $34(61)$ \\
\hline Primary school & $8(14)$ \\
\hline Middle School & $5(9)$ \\
\hline High school & $1(1)$ \\
\hline University & \\
\hline Occupation, $n(\%)$ & $22(40)$ \\
\hline Housewife & $2(3)$ \\
\hline Student & $4(7)$ \\
\hline Officer & $1(1)$ \\
\hline Worker & $4(7)$ \\
\hline Self-employment & $22(40)$ \\
\hline Retired & $6(10)$ \\
\hline Yes & $49(89)$ \\
\hline No & \\
\hline
\end{tabular}

Table 2. Comparison of Beck Depression Inventory and Beck Anxiety Inventory total scores

\begin{tabular}{|cccc|} 
Scale & $\begin{array}{c}\text { Total score, } \\
\text { Mean } \pm \text { SD }\end{array}$ & $\begin{array}{c}\text { One-sample test } \\
\boldsymbol{p} \text {-value }\end{array}$ & $\begin{array}{c}\text { Correlation test } \\
\boldsymbol{p} \text {-value, } \boldsymbol{r}\end{array}$ \\
\hline $\mathrm{BDI}$ & $15.05 \pm 8.941$ & 0.112 & $\begin{array}{c}p=0.000 \\
r=0.782\end{array}$ \\
\hline $\mathrm{BAl}$ & $13.44 \pm 8.664$ & 0.033 & \\
\hline
\end{tabular}

BDI - Beck Depression Inventory, BAI - Beck Anxiety Inventory.

\section{Statistical analysis}

Statistical analysis of data was performed using IBM SPSS v.22.0 version. One-way ANOVA and Pearson Correlation test were used for normal distribution values in non-categorical data, and the Mann-Whitney $U$ test was used for non-parametric data. Categorical data were compared with $\chi^{2}$ test. The significance level was accepted as $p<0.05$.

\section{RESULTS}

Fifty-five adult cancer patients were included in the study. The sociodemographic characteristics of the participants are shown in Table $1.40 \%$ of the participants were female, and the mean age was 59.2 \pm 12.7 (33-82) years. The majority of the participants $(92 \%)$ were married. The level of education, occupation, and history of previously diagnosed psychiatric disease were low $(p<0.001)$.

BDI and BAI scores of the participants were evaluated (Table 2). It was found that they were not depressed in terms of total BDI scores $(p=0.112)$ and they were in anxiety in terms of total BAI scores $(p=0.033)$. There was a statistically significant correlation between depression and anxiety $(p<0.001$, $r=0.782)$. As depression increased, anxiety increased (Table 2).

Pain Catastrophising Scale subscale scores of the patients with and without depression according to BDI total scores of the participants and the patients with and without anxiety according to the BAI total scores are shown in Table 3. Pain Catastrophising Scale total score and the 'helplessness' and 'rumination' subscale scores were significantly higher in cancer patients with depression than BDI compared to those without depression $(p<0.001)$. There was no statistically significant difference in PCS 'magnification' score $(p=0.105)$. Pain Catastrophising Scale total score and 'helplessness', 'magnification', and 'rumination' scores were significantly higher in cancer patients with anxiety than BAI compared to cancer patients without anxiety $(p<0.001)$. This indicates a positive correlation between depression and anxiety and pain catastrophising (Table 3).

PCS total scores of the participants according to BDI and BAI subscale scores are shown in Table 4 . There was a statistically significant correlation between PCS total score and BDI subscales: 'borderline clinical depression' $(p=0.041)$, 'moderate depression', 'severe depression', and BAI subscales: 'moderate anxiety', 'severe anxiety' $(p<0.001)$. As BDI and BAI severity increased, PCS total scores increased statistically (Table 4).

BDI and BAI scores were $2.54 \pm 1.36$ and 2.35 \pm 0.99 for females, $2.24 \pm 1.35$ and $2.05 \pm 1.02$ for males, and there was a statistically significant difference in terms of gender $(p<0.001)$. There was no significant difference between the genders in terms of PCS total scores $(p=0.43)$.

\section{DISCUSSION}

In our study evaluating the relationship between depression and anxiety and pain catastrophising in cancer patients, it was found that the depression scores of the patients were normal but the anxiety scores were high, the depression and anxiety were related, and the pain catastrophising increased with the severity of depression and anxiety. Cancer pa- 
Table 3. Pain Catastrophizing Scale subscale scores according to the presence of depression or anxiety

\begin{tabular}{lccc} 
Subscales & No depression (BDI), mean \pm SD & Depression (BDI), mean \pm SD & \multicolumn{1}{c}{$p$-value } \\
Helplessness & $10.90 \pm 0.58$ & $13.43 \pm 4.302$ & 0.000 \\
\hline Magnification & $7.19 \pm 3.071$ & $6.91 \pm 2.240$ & 0.105 \\
\hline Rumination & $8.99 \pm 4.204$ & $10.95 \pm 2.898$ & 0.000 \\
\hline Total & $27.06 \pm 13.287$ & $31.28 \pm 7.997$ & 0.000 \\
\hline Helplessness & No Anxiety (BAI) & Anxiety (BAI) & p-value \\
\hline Magnification & $10.27 \pm 6.259$ & $14.40 \pm 4.498$ & 0.000 \\
\hline Rumination & $6.82 \pm 3.037$ & $7.57 \pm 2.307$ & 0.000 \\
\hline Total & $8.61 \pm 3.888$ & $11.50 \pm 3.231$ & 0.000 \\
\hline
\end{tabular}

BDI - Beck Depression Inventory, BAI - Beck Anxiety Inventory.

Table 4. Pain Catastrophising Scale total scores by Beck Depression Inventory and Beck Anxiety Inventory subscale scores

\begin{tabular}{ccccc} 
Scale & & PCS Total score mean \pm SD & Mean difference (I-J) \pm SS & p-value \\
BDI & Normal & $27.04 \pm 14.946$ & - & - \\
\cline { 2 - 5 } & Mild mental distress & $27.08 \pm 11.466$ & $-0.040 \pm 0.823$ & 1.00 \\
\hline Borderline clinical depression & $23.56 \pm 4.733$ & $3.481 \pm 1.243$ & 0.041 \\
Moderate depression & $32.49 \pm 6.348$ & $-5.450 \pm 1.084$ & 0.000 \\
\hline BAI & $35.97 \pm 7.295$ & $-8.934 \pm 1.133$ & 0.000 \\
\hline Severe depression & Normal & - & - \\
\hline Mild mental distress & $26.54 \pm 14.994$ & $1.662 \pm 0.829$ & 0.187 \\
\hline Borderline clinical depression & $33.07 \pm 9.319$ & $-6.530 \pm 0.917$ & 0.000 \\
\hline Moderate depression & $34.12 \pm 8.142$ & $-7.580 \pm 1.073$ & 0.000 \\
\hline
\end{tabular}

BDI - Beck Depression Inventory, BAI - Beck Anxiety Inventory, PCS - Pain Catastrophising Scale.

tients desire emotional support and the availability of someone with whom they can talk about their fears and concerns [17]. There are many emotional and behavioural reactions starting from the diagnosis and continuing during and after treatment in cancer patients. When cancer patients are treated for the first time, they are under enormous stress. The type of cancer, the method of treatment, and with cancer recurrence probably also influence the results. The longer the illness continues, the weaker their internal motivation becomes [18]. Some studies have shown marital conditions as a prominent risk factor for depression and anxiety among women [19]. Reactions seen in this period include denial of diagnosis, which is a defence against the feelings of anxiety and helplessness created by the fact that is difficult to bear. Anger and depression may develop afterwards [20]. In a meta-analysis by Mitchell et al., one-sixth of the cancer patients under treatment had depression and one-fourth had other mood disorders [21]. In the study of Ferrario et al., the anxiety level in cancer patients was found to be higher than in the normal population [22]. In patients included in our study both depression and anxiety scores were significantly higher in women than men. When the whole patient group was evaluated, it was found that the depression scores of the patients were higher than the anxiety scores, and there was a positive correlation between depression and anxiety. Both psychiatric conditions are interrelated and can increase each other from time to time. Anxiety, depression, and anger levels were reported to be significantly higher in cancer patients with pain than in those without pain [23]. The stage of cancer is associated with depression. Especially in advanced cancer disease, depression follows pain. This supports the need to integrate pain assessment in the evaluation of depression, especially in metastatic cancer [24]. Metastatic cancer patients may have additional findings such as heart findings [25]. There is a high degree of variability in the levels of physical and psychological adaptation to chronic pain in cancer, and patients with cancer use many strategies to manage pain [26]. Research has shown that patients who used adaptive coping strategies such as ignoring pain sensations, praying/hoping, and self-statements are more able to reduce and control the pain compared to those who used nonadaptive strategies 
such as catastrophising [27]. Three pain beliefs that have been shown to put patients at greatest risk of a poor prognosis are pain catastrophising (an exaggerated, negative interpretation of pain), fear avoidance (a belief that all activity should be avoided to reduce pain), and poor expectations for recovery [28]. Patients with high levels of pain catastrophising report more severe depression and anxiety, more severe pain level, and lower levels of recovery, while patients with adaptive coping strategies have less pain and less stress [8, 10-12]. In our study, PCS total score and 'helplessness' and 'rumination' subscale scores were higher than in cancer patients with depression and anxiety, and 'magnification' subscale scores were higher in cancer patients with anxiety. Hence, it was found that depression and anxiety catastrophised pain and increased helplessness and ruminative thoughts, and anxiety increased thoughts about magnifying pain. In our study, it was found that total pain catastrophising was increased if there was an increase in 'borderline clinical depression', 'moderate depression', 'severe depression', 'moderate anxiety', and 'severe anxiety' scores. Thus, it was found that depression and anxiety in cancer patients increased pain catastrophising both in total score and subscale scores, and also as the degree of depression and anxiety increased, catastrophic pain increased in a correlated manner. Research has been consistent in showing that measures of catastrophic thinking are significantly correlated with measures of depression, anxiety, and fear [8]. In a study among haemodialysed patients it has been established that pain and self-sufficiency for daily activities are factors of an increase in the stress experienced [29]. In our study, depression and anxiety scores were found to be significantly higher in female patients than in men, but no significant difference was found between the genders in terms of pain catastrophising. Similarly, in some studies women reported greater use of pain catastrophising compared to men [30]. Davis et al. reported in their study that women in chronic pain reported both a more negative affect in response to stressors and a more positive affect in response to beneficial events [31]. The psychological status of patients may change as the duration of the disease increases in cancer. One of the most important limitations of our study was that only early-stage patients were included, and the number of patients was low.

\section{CONCLUSIONS}

Psychological factors have major effects on cancer pain; however, the impact of psychological distress is often underestimated, and cancer pain is usually treated medically. Health professionals giving care to cancer patients need to be alert to signs of psychological distress in patients experiencing pain, and they should consider psychological and behavioural treatments to manage cancer pain.

The authors declare no conflict of interest.

\section{REFERENCES}

1. Krajewski W, Mazur M, Poterek A, et al. Assessment of pain management, acceptance of illness, and adjustment to life with cancer in patients with nonmuscle invasive bladder cancer. BioMed Res Int 2018; 2018.

2. Arslan D, Tatlı AM, Üyetürk Ü. Kansere bağlı ağrı ve tedavisi. Abant Med J 2013; 2: 256-260.

3. Abernethy AP, Samsa GP, Matchar DB. A clinical decision and economic analysis model of cancer pain management. Am J Manag Care 2003; 9: 651-664.

4. Cederberg JT, Weineland S, Dahl J, et al. Validation of the Swedish version of the pain catastrophizing scale for parents (PCS-P) for parents of children with cancer. J Pain Res 2019; 12: 1017-1023.

5. İnci $\mathrm{H}$, Kılınçel $\mathrm{O}$, İnci $\mathrm{F}$, et al. Comparison of stress coping attitudes in caregivers for cancer and non-cancer patients on palliative care. Med Paliat 2020; 12: 18-24.

6. Syrjala KL, Jensen MP, Mendoza ME, et al. Psychological and behavioral approaches to cancer pain management. J Clin Oncol 2014; 32: 1703-1711.

7. Odynets T, Briskin Y, Todorova V, et al. Impact of different exercise interventions on anxiety and depression in breast cancer patients. Physiotherap Quart 2019; 27: 31-36.

8. Sullivan MJ, Bishop SR, Pivik J. The pain catastrophizing scale: development and validation. Psycholog Assess 1995; 7: 524.

9. Buenaver LF, Edwards RR, Smith MT, et al. Catastrophizing and pain-coping in young adults: associations with depressive symptoms and headache pain. J Pain 2008; 9: 311-319.

10. Prasertsri N, Holden J, Keefe FJ, et al. Repressive coping style: relationships with depression, pain, and pain coping strategies in lung cancer outpatients. Lung Cancer 2011; 71: 235-240.

11. Rezaei S, Afsharnezhad T, Kafi M, et al. Relationship between depression and coping strategies in chronic back pain patients. Daneshvar Med 2009; 16: 63-74.

12. Linton SJ, Shaw WS. Impact of psychological factors in the experience of pain. Phys Ther 2011; 91: 700-711.

13. Beck AT, Ward CH, Mendelson $\mathrm{M}$, et al. An inventory for measuring depression. Arch Gen Psychiatry 1961; 4: 561-571.

14. Hisli N. Beck depresyon envanterinin universite ogrencileri icin gecerliligi, guvenilirligi.(A reliability and validity study of beck depression inventory in a university student sample). J Psychol 1989; 7: 3-13.

15. Beck AT, Epstein N, Brown G, et al. An inventory for measuring clinical anxiety: psychometric properties. J Consult Clin Psychol 1988; 56: 893-897.

16. Ulusoy M. Beck anksiyete envanteri-geçerlik ve güvenirlik çalışması (Yayınlanmamış uzmanlık tezi). 1993.

17. Brandt-Salmeri A, Przybyła-Basista H. Depression and marital satisfaction: the mediating role of sexual satisfaction and perceived partner acceptance in women after mastectomy. Health Psychol Rep 2019; 7: 121-132.

18. Gibek K, Sacha T. Comparison of health locus of control in oncological and non-oncological patients. Contemp Oncol 2019; 23: 115 .

19. Yazdanpanahi $Z$, Beygi $Z$, Bagheri S, et al. An investigation into the correlation of marital adaptation with stress, anxiety, 
depression and sexual function and its components. Fam Med Primary Care Rev 2019; 21: 264-269.

20. Ateşçi FÇ, Oğuzhanoğlu NK, Baltalarli B, et al. Psychiatric disorders in cancer patients and associated factors. Turk Psikiyatri Derg 2003; 14: 145-152.

21. Mitchell AJ, Chan M, Bhatti H, et al. Prevalence of depression, anxiety, and adjustment disorder in oncological, haematological, and palliative-care settings: a meta-analysis of 94 interviewbased studies. Lancet Oncol 2011; 12: 160-174.

22. Rossi Ferrario S, Zotti AM, Massara G, et al. A comparative assessment of psychological and psychosocial characteristics of cancer patients and their caregivers. Psychooncology 2003; 12 : 1-7.

23. Glover J, Dibble SL, Dodd MJ, et al. Mood states of oncology outpatients: does pain make a difference? J Pain Symptom Manage 1995; 10: 120-128.

24. Tan SM, Beck KR, Li H, et al. Depression and anxiety in cancer patients in a Tertiary General Hospital in Singapore. Asian J Psychiatry 2014; 8: 33-37.

25. Beşler MS, Canpolat U. Cardiac metastasis mimicking acute ST-elevation myocardial infarction. Anatolian J Cardiol 2019; 22: E1b.

26. Bishop SR, Warr D. Coping, catastrophizing and chronic pain in breast cancer. J Behav Med 2003; 26: 265-281.

27. Tabriz ER, Mohammadi R, Roshandel GR, et al. Pain beliefs and perceptions and their relationship with coping strategies, stress, anxiety, and depression in patients with cancer. Indian J Palliat Care 2019; 25: 61-65.

28. Nicholas MK, Linton SJ, Watson PJ, et al. Early identification and management of psychological risk factors ("yellow flags") in patients with low back pain: a reappraisal. Phys Ther 2011; 91: 737-753.

29. Starczewska M, Wojewska D, Schneider-Matyka D. Assessment of stress level and prevalence of depression among haemodialyzed patients. Fam Med Primary Care Rev 2020; 22 216-221.

30. Meints SM, Stout M, Abplanalp S, et al. Pain-related rumination, but not magnification or helplessness, mediates race and sex differences in experimental pain. J Pain 2017; 18: 332-339.

31. Davis MC, Okun MA, Kruszewski D, et al. Sex differences in the relations of positive and negative daily events and fatigue in adults with rheumatoid arthritis. J Pain 2010; 11: 1338-1347. 